\title{
El repensar de la capacidad jurídica de las personas con discapacidad ante el modelo social: caso México
}

Trethinking the legal capacity of persons with disabilities before the social model: case of mexico Repensar a capacidade jurídica das pessoas com incapacidade frente ao modelo social: o caso méxico

DOI: http://dx.doi.org/10.21803\%2Fpenamer.11.21.535

Gisela María Pérez Fuentes https://orcid.org/0000-0001-7616-9193

Margarita del Carmen Rodríguez Collado https://orcid.org/0000-0002-1728-293

\section{¿Cómo citar este artículo?}

Peréz, G. \& Rodriguez, M. (2018). El repensar de la capacidad jurídica de las personas con discapacidad ante el modelo social: caso méxico. Pensamiento Americano, 11(21), 217-228 http://dx.doi.org/10.21803\%2Fpenamer.11.21.535

\section{Resumen}

El objetivo de este artículo es analizar los modelos a través de los cuales se ha tratado a la discapacidad, para explicar la nueva concepción de la persona con esta condición en México según los principios que establece el modelo social, en virtud de que la promulgación en 2006 de la Convención sobre los Derechos de las Personas con discapacidad marca un rompimiento con el concepto y el tratamiento médico-rehabilitador de la discapacidad.

PALABRAS CLAVE: discapacidad, capacidad jurídica, derechos.

\section{Abstract}

The objective of this article is to analyze the models through which disability has been treated, to explain the new conception of the person with this condition in Mexico according to the principles established by the social model, by virtue of the fact that the promulgation in 2006 of the Convention on the Rights of Persons with Disabilities marks a break with the concept and medical-rehabilitative treatment of disability.

KEYWORDS: disability, legal capacity, rights. 


\section{Resumo}

O objetivo deste artigo é analisar os modelos através dos quais se tratou a incapacidade, para explicar a nova concepção das pessoas com essa condição no México. Segundo os princípios que estabelece o modelo social, em virtude de que a promulgação em 2006 da Convenção sobre os Direitos das Pessoas com incapacidade marca uma ruptura com o conceito e o tratamento médico-reabilitador da incapacidade.

PALAVRAS CHAVE: incapacidade, capacidade jurídica, direitos.

\section{Perfil}

Doctora en Derecho. Pertenece al SNI nivel III de CONACYT. Responsable del Doctorado en Estudios Jurídicos en la Universidad Juárez Autónoma de Tabasco, certificado por Conacyt. Líder del Cuerpo Académico Estudios de Derecho Civil. giselapef@hotmail.com

\section{Perfil}

Maestra en Estudios Jurídicos y actualmente estudiante del Doctoradoen Estudios Jurídicos (PNPC-CONACYT) en la Universidad Juárez Autónoma de Tabasco.

margaritrc11@hotmail.com

Gisela María Pérez Fuentes

Licenciada en abogacia

Margarita del Carmen Rodríguez Collado

Licenciada en abogacia 


\section{Introducción}

En la actualidad, con el repensar del derecho civil nos encontramos ante la revalorización del concepto de persona y es por ello, que también existe una nueva forma de proteger los derechos y dignidad de las personas que tienen una discapacidad.

El concepto de discapacidad ha sido un término evolutivo, según Kuhn (1971) existe una revolución científica cuando el paradigma predominante en determinada ciencia ya no responde satisfactoriamente a todas las situaciones existentes, por tanto, los avances en la ciencia en sus distintos ámbitos han permitido superar el tratamiento médico-rehabilitador de la discapacidad, como menciona Palacios (2008) a las personas con discapacidad mental en ciertas ocasiones se les negaba (aún se sigue negando) el status de ciudadanos titulares derechos convirtiéndolos en objetos de leyes caritativas, pero ante el modelo social de discapacidad se busca lograr el ejercicio y reconocimiento pleno de los derechos humanos y dignidad de este grupo de personas, por lo cual, el objetivo general de este artículo es analizar el tratamiento de la capacidad jurídica de las personas con discapacidad en materia civil en México.

\section{Modelos de tratamiento de la Discapacidad}

En la antigüedad la discapacidad era asociada con el castigo divino y el tratamiento más común que se les otorgaba era el exterminio. Con la llegada del cristianismo las personas con discapacidad se convierten en un medio para demostrar la caridady la beneficencia. Pérez Castro (2014). Inicialmente los modelos que explicaban la discapacidad eran el modelo de prescindencia y el médico, el primero "se caracterizaba por la consideración de la discapacidad como una situación producto de un castigo divino o natural" (De Asís, 2008, p.18.), el modelo médico "considera la discapacidad como un problema de la persona directamente causado por una enfermedad, trauma o condición de salud, que requiere de cuidados médicos prestados en forma de tratamiento individual por profesionales" (Vanegas García \& Gil Ovando,2007,p.59).

En palabras de la socióloga mexicana Pérez Castro (2014), todavía a finales del siglo XIX prevaleció la tendencia a la reclusión y a la negación de las posibilidades de desarrollo e integración social de las personas con discapacidad, no es sino hasta después de las dos guerras mundiales, que se impulsaron la promulgación de leyes para facilitar la reincorporación en la vida personal, familiar, laboral y social de las personas afectadas físicamente por los conflictos bélicos.

En el siguiente esquema se encuentran representados los modelos a través de los cuales se ha tratado la discapacidad, según el Instituto Interamericano del Niño (2001).

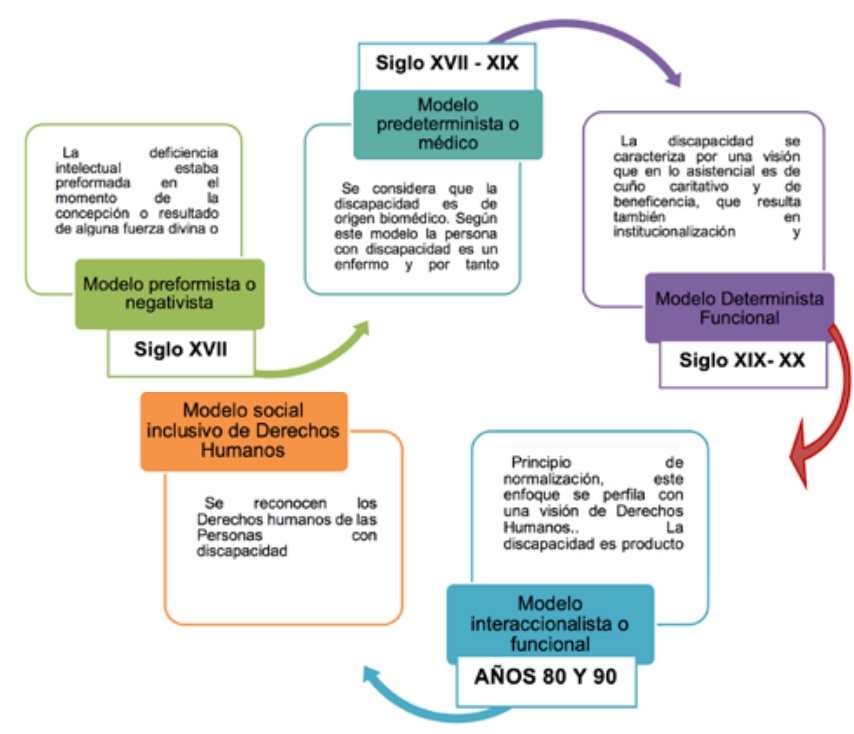

Figura 1. Modelos de tratamiento de la discapacidad.

Fuente: Elaboración propia.

\section{El modelo social de discapacidad}

El reconocimiento de la discapacidad como una cuestión social, es un avance en el tratamiento que se le ha otorgado a los derechos de las personas con discapacidad, actualmente se 
está construyendo un modelo social de discapacidad que considera que la discapacidad no solamente está relacionada con las limitaciones derivadas de la condición de la persona, sino con el contexto social en el que se encuentra.

El modelo social de discapacidad "comenzó a construirse a finales de los sesenta y principios de los setenta del siglo XX en los Estados Unidos e Inglaterra a partir de las aspiraciones y reivindicaciones del propio movimiento asociativo de las personas con discapacidad, y que se fraguó internacionalmente bajo el impulso de movimientos como el de Vida Independiente y de organizaciones como Disabled Peoples's International (DPI)" (Sánchez Martínez \& Solar Cayón, 2015, pp.26-27).

El modelo social considera que "el origen de la discapacidad obedece a causas preponderantemente sociales, es decir, a una construcción y un modo de opresión social; se basa en una nueva forma de pensar y entender, que se contrapone al paradigma representado en el modelo médico" (INADI, 2016, p.18)

El modelo social de discapacidad reafirma el derecho de las personas con discapacidad a ser sujetos titulares de derecho, basado en la protección de sus derechos humanos y dignidad. Como menciona Boss (2012) hablar de derechos humanos es aludir a la categoría universal por la cual cada persona se reconoce humana ante los demás, ante el Estado, ante la humanidad (p.19)

Asimismo, la Suprema Corte de Justicia de la Nación, máximo tribunal en México en tesis aislada reconoce que la discapacidad debe ser entendida desde el modelo social

...conforme al modelo social, la discapacidad debe ser considerada como una desventaja causada por las barreras que la organización social genera al no atender de manera adecuada las necesidades de las personas con diversida- des funcionales... Específicamente en el caso de las obligaciones de paternidad menciona "... Con base en este paradigma, si de la situación de discapacidad se derivan limitantes para hacer frente a sus obligaciones de padre, se debe constatar que éstas no sean producto de las barreras contextuales. Esto es, que no surjan debido a las diversidades funcionales per se, sino de la interacción de éstas con ciertas barreras sociales... [Tesis: 1a. XI/2016 (10a.), enero de 2016].

Un logro en la evolución jurídica de protección de los derechos de las personas con discapacidad puede verse reflejado en la Constitución Política de la Ciudad de México (México) en este ordenamiento en el artículo 11 cuyo título es "ciudad incluyente" se encuentran protegidos los derechos de ciertos grupos en situación de vulnerabilidad como son las personas con discapacidad, al respecto señala:

1. Esta Constitución reconoce los derechos de las personas con discapacidad. Se promoverá la asistencia personal, humana o animal, para su desarrollo en comunidad. Las autoridades adoptarán las medidas necesarias para salvaguardar integralmente el ejercicio de sus derechos y respetar su voluntad, garantizando en todo momento los principios de inclusión y accesibilidad, considerando el diseño universal y los ajustes razonables. 2. Las autoridades deben implementar un sistema de salvaguardias y apoyos en la toma de decisiones que respete su voluntad y capacidad jurídica... (Art. 11, CCM, 2017)

Si bien es cierto en la Constitución Política de los Estados Unidos Mexicanos se encuentra protegido el principio pro persona el cual garantiza que debe aplicarse la normativa que mayor favorezca a la persona, sin considerar la jerarquía de aplicación de la norma, el hecho de que en la constitución de la capital mexicana se reconozcan los derechos de las personas con discapacidad y el sistema de apoyo en la toma de 
decisiones, debe entenderse como un avance en la armonización de todas las normativas del País, ya que como eje rector de las normativas de esa entidad de la república, es relevante el reconocimiento de los derechos humanos que se advierten para todas las personas.

\section{La Convención sobre los Derechos de las per- sonas con discapacidad}

La Convención sobre los derechos de las personas con discapacidad y su Protocolo Facultativo fueron aprobados el 13 de diciembre de 2006 en la Sede de las Naciones Unidas en Nueva York, aprobados por México el 24 de octubre de 2007 e iniciando su vigencia el 3 de mayo de 2008.

La promulgación de esta convención "representa un cambio en el tratamiento de la discapacidad, representa la superación definitiva, en el contexto internacional, del modelo médico y la asunción del llamado «modelo social», que inscribe plenamente la temática de los derechos de las personas con discapacidad en el ámbito de los derechos humanos"
(Sánchez Martínez \& Solar Cayón, 2015, p.26).

El objetivo principal de la Convención es "promover, proteger y asegurar el goce pleno y en condiciones de igualdad de todos los derechos humanos y libertades fundamentales por todas las personas con discapacidad, y promover el respeto de su dignidad inherente." (Artículo 1, Convención sobre los Derechos de las Personas con Discapacidad, 2006)

Con la entrada en vigor en México de este tratado internacional, se genera una transformación en la visión de la discapacidad y el ejercicio de los derechos de las personas con discapacidad, ya que se consagran a nivel internacional los siguientes principios: el respeto de la dignidad inherente, la autonomía individual y la independencia de las personas, la no discriminación, la participación e inclusión plenas y efectivas en la sociedad, el respeto por la diferencia y la aceptación de las personas con discapacidad, la igualdad de oportunidades, la accesibilidad y la igualdad entre el hombre y la mujer (De Los Rios, 2012).

\section{CONVENCIÓN SOBRE LOS DERECHOS DE LAS PERSONAS CON DISCAPACIDAD}

\section{Objetivo}

\begin{tabular}{|c|c|c|c|}
\hline \multicolumn{4}{|c|}{ Derechos } \\
\hline $\begin{array}{l}\text { Art. } 5 \text { Derecho a } \\
\text { la igualdad y no } \\
\text { discriminación. }\end{array}$ & $\begin{array}{l}\text { Ar. } 13 \text { Derecho } \\
\text { de acceso a la } \\
\text { justicia }\end{array}$ & $\begin{array}{l}\text { Art. } 19 \text { Derecho a vivir de } \\
\text { forma independiente y a } \\
\text { ser incluido en la } \\
\text { comunidad }\end{array}$ & $\begin{array}{l}\text { Art. } 25 \text { Derecho } \\
\text { a la salud }\end{array}$ \\
\hline $\begin{array}{l}\text { Ar. } 6 \text { Derecho de } \\
\text { las mujeres con } \\
\text { discapacidad }\end{array}$ & $\begin{array}{l}\text { Art. } 14 \text { Derechola } \\
\text { Libertad y seguridad } \\
\text { de la persona }\end{array}$ & $\begin{array}{l}\text { Art. 20 Derecho } \\
\text { a la Movilidad } \\
\text { personal }\end{array}$ & $\begin{array}{l}\text { Art. } 26 \text { Derecho } \\
\text { a la Habilitación } \\
\text { y rehabilitación }\end{array}$ \\
\hline $\begin{array}{l}\text { Art. } 7 \text { Derecho de } \\
\text { los niños y niñasas } \\
\text { con discapacidad }\end{array}$ & $\begin{array}{l}\text { Art. } 15 \text { Derecho a la } \\
\text { protección contra la } \\
\text { tortura y tratos } \\
\text { crueles e inhumanos. }\end{array}$ & $\begin{array}{l}\text { Art. } 21 \text { Derecho a la } \\
\text { Libertad de expresión } \\
\text { y de opinión y acceso } \\
\text { a la información }\end{array}$ & $\begin{array}{l}\text { Art. } 27 \text { Derecho } \\
\text { al Trabajo y } \\
\text { empleo }\end{array}$ \\
\hline $\begin{array}{c}\text { Art. } 9 \text { Derecho } \\
\text { a la } \\
\text { accesibilidad. }\end{array}$ & $\begin{array}{l}\text { Ar. } 16 \text { Derecho a la } \\
\text { Protección contra } \\
\text { la explotación, la } \\
\text { violencia y el abuso }\end{array}$ & $\begin{array}{c}\text { Art. } 22 \\
\text { Derecho a la } \\
\text { privacidad }\end{array}$ & $\begin{array}{c}\text { Art. } 28 \text { Derecho a } \\
\text { Nivel de vida } \\
\text { adecuado y protección } \\
\text { social }\end{array}$ \\
\hline $\begin{array}{c}\text { Art. } 10 \text { Derecho } \\
\text { a la vida }\end{array}$ & $\begin{array}{l}\text { Art. } 17 \text { Derecho } \\
\text { a la protección } \\
\text { integral }\end{array}$ & $\begin{array}{l}\text { Art. } 23 \text { Derecho } \\
\text { a la familia }\end{array}$ & $\begin{array}{l}\text { Art. } 29 \text { Derecho a } \\
\text { Participación en la } \\
\text { vida politica y pública }\end{array}$ \\
\hline $\begin{array}{l}\text { Ar. } 12 \text { Derecho al } \\
\text { Igual reconocimiento } \\
\text { como persona ante la } \\
\text { ley }\end{array}$ & $\begin{array}{l}\text { Art. } 18 \text { Derecho a la } \\
\text { Libertad de } \\
\text { desplazamiento y } \\
\text { nacionalidad }\end{array}$ & $\begin{array}{c}\text { Art. } 24 \\
\text { Derecho a la } \\
\text { educación }\end{array}$ & $\begin{array}{l}\text { Art } \\
\text { Participare en la vida } \\
\text { cultural, las actividades } \\
\text { recreativas el el } \\
\text { esparcimiento y el deporte }\end{array}$ \\
\hline
\end{tabular}

Figura 2. Contenido esencial de la Convención sobre los Derechos de las Personas con Discapacidad. Fuente: Elaboración propia 


\section{La constitucionalización del derecho civil y su influencia en el menor del siglo XXI}

El derecho civil se ha constitucionalizado, qué significa ello, algo tan sencillo y a la vez complejo que impone a los operadores del derecho cuestionarse principios clásicos del derecho romano pues el derecho civil vigente es expresión de un ordenamiento unitario siempre caracterizado por la centralidad de la legalidad inspirada en los valores fundamentales de la Constitución. En la cúspide se encuentra la persona como valor y las formaciones sociales en las que las personas son llamadas a realizar su pleno y libre desarrollo (Perlingieri, 2008, p 13)

Lo anterior implica en primer lugar, que la persona ha recuperado su lugar preponderante en el sistema jurídico de muchos países en los que se encuentra México y ello se hace a extensivo al menor en segundo lugar, que no es simplemente incapaz por no contar con 18 años. El menor del siglo XXI muestra un constante desarrollo en los aspectos psicosocial, cognitivo y moral, todo ello ha permitido un aumento progresivo de las funciones del ser humano desde sus edades más tempranas. (Pérez Fuentes, 2017, p. 38)

\section{Capacidad Jurídica ¿Sí o no?}

El problema de la discapacidad es muy amplio e interdisciplinar, la situación actual obliga a mirar hacia el tratamiento jurídico del tema, con el repensar del derecho de Familia y el derecho Civil nos encontramos ante la revalorización del concepto de persona y es por ello, que debe existir un repensar de la forma de proteger los derechos y dignidad de las personas que presentan una discapacidad.

Según lo establece el artículo 12 de la Convención sobre los Derechos de las Personas con Discapacidad, las personas con discapacidad tienen derecho en todas partes al reconocimiento de su personalidad jurídica y de su capacidad jurídica en igualdad de condiciones con las demás en todos los aspectos de la vida.

Es importante señalar que los efectos jurídicos del mencionado artículo han evolucionado desde la adhesión a la convención hasta la época actual, ya que México al momento de adherirse a la presente convención realiza una declaración interpretativa del artículo 12 en los siguientes términos:

...el Estado Mexicano reitera su firme compromiso de generar condiciones que permitan a toda persona, a desarrollarse de modo integral, así como ejercer sus derechos y libertades plenamente y sin discriminación. Consecuentemente, con la absoluta determinación de proteger los derechos y la dignidad de las personas con discapacidad, los Estados Unidos Mexicanos interpretan el párrafo 2 del artículo 12 de la Convención, en el sentido de que en caso de conflicto entre dicho párrafo y la legislación nacional habrá de aplicarse -en estricto apego al principio pro homine- la norma que confiera mayor protección legal, salvaguarde la dignidad y asegure la integridad física, psicológica, emocional y patrimonial de las personas. (Decreto, 2008)

No obstante, por decreto publicado en diciembre de 2011, se retiró la mencionada reserva y actualmente el artículo 12 tiene efectos plenos para México.

En este artículo se protege a la persona con discapacidad y se busca situarla en un plano de igualdad con todos los demás sujetos que conforman la sociedad.

Pero ¿Qué es la personalidad jurídica? y ¿Qué es la capacidad jurídica? En palabras de Pérez Fuentes y Cantoral Domínguez (2015) "La personalidad es definida como la cualidad ju- 
rídica inviolable y objetiva que se adhiere a la sustancia hombre desde su nacimiento para conformar el concepto de persona" (p.13), reconocida y protegida por instrumentos internacionales, esta concepción de la personalidad busca recobrar el valor de la persona en sí misma y no por lo que posee, alejándose de la concepción romana de la persona.

No obstante, aunque todas las personas tienen derecho a que se reconozca su personalidad jurídica, su capacidad de ejercicio puede estar limitada, según las condiciones especiales que reúna la persona, como es el caso de los menores y las personas con discapacidad intelectual. Cuando las limitaciones o restricciones al ejercicio de su capacidad están fundamentadas en su condición de vulnerabilidad y buscan equilibrar la desigualdad, estas son protegidas por el Derecho, por lo cual no se considera que se atenta contra los principios de igualdad y no discriminación.

La capacidad jurídica "es la condición sine quan non a los efectos del goce y ejercicio de todos los derechos, en igualdad de oportunidades" (Palacios, 2008, p.419), en otras palabras, sin capacidad jurídica no podemos gozar ni ejercer nuestros derechos de forma directa.

La capacidad jurídica está integrada por dos esferas: la capacidad de goce y la capacidad de ejercicio, en el caso de personas con discapacidad, existen diversas problemáticas derivadas de la forma de proteger la segunda, la cual tradicionalmente es definida como "la aptitud de una persona para hacer valer directamente sus derechos y cumplir sus obligaciones" (Baqueiro Rojas \& Buenrostro Baéz, 2015).

Al respecto la Corte Interamericana de Derechos Humanos sostiene: "Las limitaciones de la capacidad jurídica en nada substraen a la personalidad jurídica. El titular de derechos es el ser humano, de carne, hueso y alma, y no la condición existencial en que se encuentra." (OC-17/2002).

Así, podemos entender que las personas con discapacidad desde la visión de la Corte Interamericana de DH son seres humanos en una condición especial, dotados de personalidad, por lo cual debe protegerse el derecho a su libre determinación, a vivir de forma autónoma e independiente según sus propias limitaciones.

\section{Al respecto la Suprema Corte de Justicia de la Nación establece:}

...no debe confundirse el principio de mayor protección de la persona con discapacidad en aras de su mayor interés, con la prohibición de que la misma decida qué es lo que le beneficia, situación que redunda de forma directa en el desarrollo libre de la personalidad, así como en el fomento de una vida autónoma y de una identidad propia, sin que deba restringirse la capacidad jurídica de una persona solamente porque la misma ha tomado una opción que la generalidad de la sociedad pudiese considerar o calificar como "no acertada". ...es decir, mediante dicho modelo, se deberán generar escenarios idóneos para que se asista a las personas con discapacidad, guiándolas y aconsejándolas para que tomen sus decisiones, pero una vez que en el caso concreto se ha determinado que la asistencia es necesaria y la persona con discapacidad ha sido asistida, la voluntad que la misma externe deberá respetarse y acatarse, es decir, en el centro de las decisiones relativas a las personas con discapacidad, se encontrará la voluntad del individuo cuya capacidad ha de limitarse... [Tesis: 1a. CCCLII/2013 (10a.), diciembre de 2013].

Tal como lo interpreta la Corte Interamericana de Derechos Humanos y la Suprema Corte de Justicia de la Nación, dependiendo del grado de entendimiento, las personas con discapa- 
cidad intelectual son seres humanos autónomos, que deben ser considerados capaces por el Derecho para tomar sus propias decisiones, si bien es cierto con apoyo de acuerdo a sus necesidades, pero respetando su libre determinación, teniendo en consideración que en algunos casos como ultima ratio para otorgarle protección a la persona, las decisiones deberán ser tomadas por otro, pero siempre con las salvaguardias necesarias para lograr el mayor beneficio posible para la persona con discapacidad y, asimismo, es necesario determinar un modelo de asistencia en la toma de decisiones de las personas con discapacidad que nos permitan conceptualizar a la persona con discapacidad, como un ser humano con ciertas limitaciones en su capacidad de ejercicio o de obrar pero con personalidad jurídica plena.

De todo lo anterior es importante enmarcar la necesidad de lograr que las personas con discapacidad obtengan "el reconocimiento de sus derechos, en las peculiares circunstancias y en el establecimiento de garantías específicas para lograr su eficaz protección" (Figueruelo Burrieza,2015,p.618), de igual manera cobra importancia puntualizar, que así como existen personas con discapacidad que podrán ejercer su capacidad jurídica con necesidad de algún tipo de asistencia, habrá personas que para que el Derecho los proteja deberán tener limitada su capacidad de ejercicio y tal vez en algunos casos, deberán ser sujetos de representación, y así, otra persona o entidad tomará decisiones por ella.

En el tema de acceso a la justicia y capacidad jurídica, ¿puede una persona con discapacidad por derecho propio promover un juicio de amparo?

Tal como lo relata Núñez Escobar (2017), en 2016 promueven amparo 138 personas con discapacidad en contra de la Ley General para la Atención y Protección a Personas con la Condición del Espectro Autista, no es cuestión del artículo analizar las violaciones alegadas por los quejosos sino el proceso de tramitación del juicio de amparo, ya que al momento de conocer que los promoventes presentaban una discapacidad, se les nombró un representante especial de acuerdo a lo establecido por el artículo 8 de la Ley de Amparo, por lo cual se presentó un recurso de queja contra esta disposición debido a que al obligarlos a tener un representante especial se violaban sus derechos humanos de acceso a la justicia, igualdad ante la Ley y el reconocimiento a su personalidad y capacidad jurídica.

Al resolverse la queja se determinó: el reconocimiento del derecho de las personas con discapacidad a acudir al juicio de amparo por propio derecho, inclusive cuando hayan señalado representante legal. Las personas con discapacidad, estableció la Corte, tienen, además, el derecho de elegir a su "representante especial" y en su caso, rechazar la designación de alguno.

La resolución de esta queja es un avance en el tratamiento social de la discapacidad, debido a que se reconoce la capacidad jurídica de las personas con discapacidad y con ello se reconoce su derecho de acceso a la justicia por derecho propio aun teniendo un tutor.

Como se puede apreciar hay avances y retrocesos en el tema del tratamiento de la discapacidad con perspectiva social y de derechos humanos, ya que se deben de repensar las funciones de la figuras coadyuvantes en la protección de los derechos de las personas con discapacidad, el transitar hacia un modelo social no significa incluir en leyes y reglamentos la leyenda "la discapacidad es tratada conforme al modelo social" sino interpretar y aplicar las normativas conforme los principios del modelo social de discapacidad y así, res- 
petar auténticamente los derechos de las personas con discapacidad.

El repensar del juicio de interdicción, la tutela y curatela, como instituciones garantes de los derechos de las personas con discapacidad.

Con el modelo social del tratamiento de la discapacidad se deben repensar las funciones de figuras del derecho civil como la tutela y la curatela, asimismo el procedimiento de interdicción y el papel del juez como vigilante de la protección del espíritu de las normativas tanto nacionales como internacionales cuyo objetivo sea la máxima protección de la persona.

Aunque doctrinariamente se muestra que la finalidad de estas figuras es el apoyo de la persona con discapacidad, en la normativa las funciones han sustituido la voluntad de las personas con discapacidad

Evidencia de ello es el caso del Código Civil para el Estado de Tabasco, México, donde respecto a la interdicción se establece que en todas las decisiones respecto a la persona incapacitada, el curador deberá consultar al Juez respecto a la venta de sus bienes, gastos de hospitalización o tratamiento, pero en ningún momento se establece que es la persona con discapacidad quien tomara su decisión, en virtud de que de acuerdo a su grado de comprensión tiene derecho a opinar y a que su opinión sea tomada en cuenta para dirigir su vida.

Tal como se advierte de lo sostenido por la Suprema Corte de Justicia de la Nación, el estado de interdicción no debe suprimir la voluntad de las personas con discapacidad, sino brindar el apoyo en la toma de decisiones, por lo cual para lograr la protección jurídica integral de los derechos humanos de las personas con discapacidad es necesario establecer un modelo de asistencia para la toma de decisiones que garantice de forma efectiva el ejercicio del derecho de libre determinación, dignidad y demás derechos necesarios para proteger de forma integral a la persona con discapacidad.

Si bien es cierto que el principal objetivo de la declaración de interdicción es la protección de los derechos de las personas con discapacidad, también es cierto que tal como se encuentra regulada en el Código de estudio se genera la supresión de su voluntad, al no permitirle participar en la toma de decisiones sobre su vida que de acuerdo a su discapacidad pueda aportar.

La finalidad de la interdicción debe ser la limitación de la capacidad de ejercicio en actos delimitados en la sentencia según las condiciones específicas de la persona con discapacidad, no la supresión de toda su capacidad de ejercicio.

En el derecho comparado, encontramos el caso de España, el modelo de incapacitación adoptado por la ley de Enjuiciamiento Civil es un modelo basado principalmente en las peculiaridades de la persona y el caso concreto, así en palabras de Cristina Amunátegui de Rodriguez (2006):

...este modelo posibilita lo que se ha llamado «una incapacitación a medida de la persona», que debe construir el juez en la sentencia teniendo en cuenta sus circunstancias específicas. Ese diseño a medida debe referirse esencialmente a dos extremos: determinar la sumisión del incapaz a tutela o a curatela atendiendo a su grado de discernimiento; $y$, con independencia de lo anterior, matizar en cada caso su esfera de capacidad, determinando tanto los actos que pueda realizar él sólo, como especificando igualmente aquellos para los que necesitará de la actuación del tutor supliendo su voluntad, o del curador completando la misma... (p.9). 
Es importante señalar que se le otorga a la persona incapacitada el derecho de solicitar la modificación de la sentencia de incapacitación, asimismo, derivado de este sistema para incapacitar a una persona se debe estudiar su grado de entendimiento y el nivel de necesidad de asistencia, por lo cual, aunque la persona presente algún tipo de discapacidad mental, no será declarada de facto como incapacitada sino que se debe atender a su situación particular ya que puede ser que en algunos casos no sea necesaria la incapacitación.

Continuando con México, en pleno siglo XXI y con los tratados internacionales de derechos humanos reconocidos y protegidos por la Constitución Mexicana, en el Código Civil y de procedimientos civiles para el estado de Tabasco todavía se hace referencia a las personas con discapacidad con términos arcaicos y discriminatorios como "dementes" "perturbados" o "disminuidos", los cuales son asociados a una perspectiva contraria a los postulados del modelo social de derechos humanos.

De todo lo anterior se debe concluir que el Código Civil para el Estado de Tabasco debe contener un sistema de incapacitación acorde al modelo social de discapacidad, estableciendo un mecanismo de apoyo en la toma de decisiones de las personas con discapacidad, atendiendo a las necesidades que presente cada persona y brindando la oportunidad de que las personas con una discapacidad mental puedan tomar decisiones sobre los aspectos de su vida, si es necesario de forma asistida, todo ello conforme a lo establecido en el artículo 12 de la Convención sobre los derechos de las personas con discapacidad, en el cual se proclama el derecho de las personas con discapacidad al reconocimiento de su personalidad jurídica. Se debe buscar la protección del denominado "principio de «capacidad jurídica universal», el cual alcanza a todas las personas con discapacidad, sin ex- clusiones por razón del tipo o del grado de discapacidad" (Sánchez Martínez \& Solar Cayón, 2015, p.59), toda vez que el reconocimiento de la capacidad jurídica constituye el presupuesto o la condición imprescindible para que las personas con discapacidad puedan ser consideradas como sujetos titulares de derechos y capaces de ejercerlos.

\section{Es importante, con base en una perspectiva de derechos humanos, de derecho civil de derecho de familia y bioética, replantearse los elementos que conforman el estado de interdicción.}

Una mirada al tratamiento de la discapacidad en Suecia: impulsor de la protección de la capacidad jurídica de las personas con discapacidad.

En 1989, Suecia se convirtió en el primer Estado en abolir la tutela para adultos con discapacidad. En 1994 promulgó una ley sobre apoyo y servicios para personas con algunos tipos de discapacidades que provee de amplias garantías para personas con severas discapacidades intelectuales y físicas. González Ramos (2010).

Las figuras de apoyo a las personas con discapacidad creadas por el derecho sueco son: el mentor, el administrador, la persona de contacto, el asistente personal y el acompañante.

En la siguiente tabla se encuentran las funciones de las figuras anteriores. (González Ramos, 2010, pp.96-99).

Considero que estas figuras creadas por el derechosueco atienden al grado de apoyo que necesite la persona con discapacidad mental, ya que como se ha sostenido habrá personas que necesiten una intervención mayor en su esfera de independencia y autonomía, debido a que el grado de afectación mental no le permita tomar sus propias decisiones, pero 
habrá otras que requieran solo ciertos apoyos para poder vivir de forma independiente.

\section{Conclusiones}

En México ha quedado pendientela protección y garantía del ejercicio de los derechos de las personas con discapacidad. El modelo social de discapacidad implica retos para todos como integrantes de la sociedad, pero principalmente para el Estado como garante de los derechos humanos de las personas con discapacidad, por lo tanto, es importante replantearse los elementos del juicio de interdicción, repensar las funciones del tutor y curador, el papel del juzgador como intérprete de las normativas nacionales conforme a los principios señalados en la Convención de los derechos de las personas con discapacidad.

Si bien es cierto la realidad social y económica de Suecia es totalmente diferente a la que se vive en México, eso no implica que, como ejemplo podamos estudiar las figuras creadas para el apoyo del ejercicio de la capacidad de ejercicio de las personas con discapacidad sustentadas en una perspectiva de derechos humanos.

\section{Referencias}

Amunátegui de Rodriguez, C. (2006), “¿Crisis de la incapacitación? La autonomía de la voluntad como posible alternativa para la protección de los mayores", Revista de Derecho Privado, España, 1, enero - febrero.

Baqueiro Rojas, E. \& Buenrostro Báez, R. (2015) Derecho Civil: introducción y personas, 2da.ed., México, Oxford.

Boss, J. (2012). Los Derechos Humanos en América Latina. Pensamiento Americano,5(9).

Código Civil para el Estado de Tabasco. (2017). Última reforma.

Constitución de la Ciudad de México. (2017). Publicada en la gaceta oficial de la Ciudad de México.

Convención sobre los Derechos de las Personas con Discapacidad. Promulgada en 2006.

De Asís R., (2008) "Derechos humanos y discapacidad. Algunas reflexiones derivadas del análisis de la discapacidad desde la teoría de los derechos", en I. Campoy Cervera y A. Palacios (coords.), Igualdad, no discriminación y discapacidad, España, Dykinson.

De los Ríos, J. (2012) Los derechos fundamentales y el respeto por la diferencia: fundamentos del Estado Constitucional de Derecho. Pensamiento Americano, 5(8), 77-85.

Declaración Universal sobre los Derechos Humanos.

Decreto promulgatorio de la Convención sobre los Derechos de las Personas con Discapacidad y Protocolo Facultativo publicado en el Diario Oficial de la Federación el 2 de mayo de 2008.

Estado de interdicción. Acorde al modelo de asistencia en la toma de decisiones, la persona con discapacidad externará su voluntad, misma que será respetada y acatada. Tesis: 1a. CCCLII/2013 (10a.), Semanario Judicial de la Federación, Décima Época, Tomo I, diciembre de 2013.

Figueruelo Burrieza A. (2015), "La discapacidad como derecho humano, perspectiva constitucional" en M. Carbonell, H. Fix-Fiero, L.R. González Pérez y D. Valadés Ríos (coords.), Estado constitucional, derechos humanos, justicia y vida universitaria, México, IIJ-UNAM. 
González Ramos, A.K., (2010) Capacidad Jurídica de las personas con discapacidad, México, Comisión Nacional de los Derechos Humanos.

Instituto interamericano del niño (2001), la inclusión de la niñez con discapacidad, Uruguay. Documento virtual recuperado de http://mww.iin.oea.org/proder/ discapacidad/Inclusion.Discapacidad.pdf

Instituto Nacional contra la Discriminación, la Xenofobia y el Racismo - INADI (2016), Discapacidad y no discriminación, Argentina.

Kuhn T.S. (1971) La estructura de las revoluciones científicas, (A. Contin) México, fondo de cultura económica (trabajo original publicado en 1962).

Modelo Social de la Discapacidad. (2016). Ajustes razonables en procedimientos de adopción. Tesis: $1 a$. XI/2016 (10a.), Semanario Judicial de la Federación, Décima Época, Libro 26, Tomo II.

Núñez Escobar, A. D., (2017) "La capacidad jurídica de las personas con discapacidad, interpretaciones de la Segunda Sala de la Suprema Corte de Justicia de la Nación al primer párrafo del artículo $8^{\circ}$ de la ley de amparo en México", Revista Latinoamericana en Discapacidad, Sociedad y Derechos Humanos, $1(1)$.

Opinión consultiva. (28 de agosto de 2002). oc-17/2002 solicitada por la Comisión Interamericana de Derechos Humanos.

Palacios, A. (2008), El modelo social de discapacidad: orígenes, caracterización y plasmación en la Convención Internacional sobre los derechos de las personas con discapacidad, Madrid, Colección CERMI, Ediciones Cinca.

Pérez Castro, J., (2014) "Elementos para el análisis de la discapacidad desde la perspectiva de la vulnerabilidad social", Revista Internacional de Educación para la Justicia Social, México, 3(2), diciembre.

Pérez Fuentes G. M., y Cantoral Domínguez, K. (2015), Daño Moral y derechos de la personalidad del menor, México, Tirant lo Blanch.

228

Pérez Fuentes, G. M. (2017); "El nuevo paradigma de la capacidad de ejercicio en caso de menores" Nexo Jurídico. Locus Regit Actum, (30), marzo.

Perlingieri, P. (2008); El Derecho Civil en la Legalidad Constitucional, Madrid, Ed. Dykinson.
Sánchez Martínez, M. O. y Solar Cayon, J. I. (2015), La Convención Internacional sobre los Derechos de las Personas con Discapacidad y su impacto en la legislación autonómica de Cantabria, España, Dikynson.

Vanegas García, J. H. y Gil Ovando, L. M. (2007), "La discapacidad una mirada desde la teoría de sistemas y el modelo biopsicosocial", Hacia la promoción de la salud, Colombia, 12, enero - diciembre.
2018, Vol. 11(21) 217-228 @ The Author(s) 2018 Reprints and permission: www.americana.edu.co 